\title{
Avaliação qualitativa e quantitativa da emissão de biogás em aterro controlado de médio porte
}

\author{
Qualitative and quantitative evaluation of biogas emissions \\ in a medium size sanitary disposal site
}

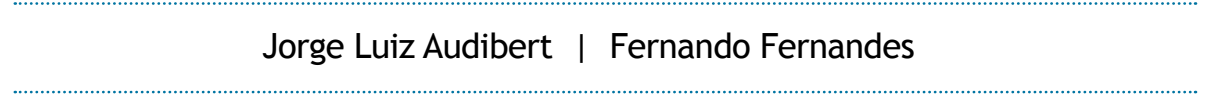

Data de entrada: 07/11/2011 | Data de aprovação: 23/07/2012

\section{Resumo}

O aterro controlado de Londrina (500.000 habitantes) é um aterro de porte médio que operou entre 1970 e 2010, sendo que no último ano recebia aproximadamente 127.750 toneladas de resíduos sólidos. A estimativa do biogás emitido foi realizada através de três campanhas entre 2009 e 2010 , distribuindo-se a área em três setores, medindo-se o biogás na saída dos drenos e na camada de cobertura. Os resultados de emissão foram comparados com a estimativa de produção de biogás, aplicandose três modelos matemáticos.

O valor médio da emissão de biogás nas três campanhas de medidas realizadas em campo foi de 34.398.731 $\mathrm{Nm}^{3} /$ ano, valor próximo aos valores obtidos por meio dos modelos matemáticos.

Palavras-chave: aterro sanitário, resíduos sólidos domésticos, emissões de biogás

\section{Abstract}

Londrina (500,000 habitants) has a medium size disposal site for Municipal Solid Waste that was in operation between 1970 and 2010. During the last year of operation (2010) the site received 127,750 t. of solid wastes. Estimations of landfill gas emissions were made in three field measurements which gave dates of gas emissions by the final cover layer and gas drains. The site was divided in 03 sectors. The results of measurements were compared with estimations of gas production using three mathematic models.

The average gas emissions measured was 34,398,731 $\mathrm{Nm}^{3} /$ year, similar to the values obtained by means of mathematical models.

Key-words: landfill, municipal solid waste, emisions of biogas

\section{Jorge Luiz Audibert*}

Engenheiro Civil pela Universidade Estadual de Londrina (UEL). Mestre em Engenharia de Edificações e Saneamento (UEL) email: jmaudibert@sercomtel.com.br

Fernando Fernandes

Professor Doutor do Departamento de Engenharia Civil da Universidade Estadual de Londrina e do Mestrado de Engenharia de Edificações e Saneamento - email: fernando@uel.br

*Endereço: Est. Achilles Pimpão Ferreira, 4001 - Cx. Postal 153 - Londrina - PR - CEP: 86.001-970 - Brasil - Tel: (43) 3334-0382 


\section{Introdução}

O biogás gerado a partir da biodegradação dos resíduos sólidos domésticos em aterros sanitários, aterros controlados e lixões é constituído por metano $\left(\mathrm{CH}_{4}\right)$, dióxido de carbono $\left(\mathrm{CO}_{2}\right)$, gás sulfídrico $\left(\mathrm{H}_{2} \mathrm{~S}\right)$ e outros gases em menor proporção. Os dois gases $\left(\mathrm{CH}_{4}\right.$ e $\left.\mathrm{CO}_{2}\right)$, reconhecidamente causadores do efeito estufa, são emitidos livremente na atmosfera na maior parte dos aterros do Brasil.

Em termos qualitativos, existem diversos fatores que podem alterar a composição do biogás de aterros municipais, entre os quais a parcela de matéria orgânica nos resíduos sólidos domésticos (RSD), a umidade desses resíduos, a forma de operação do aterro e o clima da região (MACIEL, 2003).

Estimativas teóricas da produção do biogás nos aterros podem ser realizadas por meio de modelos matemáticos disponibilizados pela literatura. No entanto, devido ao grande número de variáveis envolvidas na biodigestão da matéria orgânica dos RSD, os resultados estimados podem divergir significativamente em relação aos resultados de medidas de campo. A Agência de Proteção Ambiental dos Estados Unidos (USEPA) apresenta alguns modelos, entre os quais um modelo matemático que foi avaliado em aterros municipais dos Estados Unidos (USEPA, 1998) e um software conhecido como Landgem 3.02 (USEPA, 2005). O Painel Intergovernamental de Mudanças Climáticas apresenta alguns modelos matemáticos, entre os quais um modelo de primeira ordem (IPCC, 1996).

A emissão do biogás pela camada de cobertura de um aterro e por drenos verticais porventura existentes está relacionada com a forma de operação do aterro ao longo dos anos. Fatores como profundidade e quantidade de drenos de gases, espessura da camada de cobertura e dimensões das células onde os RSD são dispostos influenciam nas rotas do biogás no interior da massa de lixo e, conseqüentemente, nos pontos de fuga do gás para a superfície (MACIEL, 2003).

Um método utilizado para avaliação dos gases emitidos é o parcelamento do aterro em áreas menores, objetivando conhecer as características das emissões desse aterro e também aumentar a precisão dos resultados. Entretanto, não existe unanimidade na literatura com relação ao melhor método para realização das pesquisas, principalmente pela diversidade de formas de operação e locais onde os aterros se posicionam.

Neste trabalho foram realizadas as medições de vazão e determinação da composição do biogás emitido pelo aterro controlado de Londrina, cidade localizada no norte do Paraná. As determinações foram feitas nas saídas dos drenos de gás e na camada de cobertura, sendo estes resultados comparados com aqueles obtidos a partir dos modelos matemáticos considerados.

\section{Metodologia}

\section{1. $\mathrm{O}$ aterro controlado de Londrina/PR}

O município de Londrina tem população de aproximadamente 500.000 habitantes e está localizado no norte do Estado do Paraná. Tratase de um município com 75 anos de fundação e, atualmente, $97 \%$ de sua população reside na urbana (IBGE, 2010).

$\mathrm{O}$ aterro controlado de Londrina se localiza na Estrada do Limoeiro, $\mathrm{km} \mathrm{3}$, zona leste da cidade. Iniciou suas atividades no ano de 1979 e encerrou-as no ano de 2010, perfazendo aproximadamente 32 anos de operação. A forma de operação fundamental utilizada pelas empreiteiras e pela própria Prefeitura Municipal de Londrina foi a deposição do lixo em camadas de aproximadamente 3 metros de altura e compactação por meio de tratores de esteira, fazendo a camada de cobertura com solo local.

As informações obtidas junto aos gerenciadores do aterro possibilitaram a identificação macro de três grandes áreas ocupadas em épocas diferentes, utilizando como critério a idade dos RSD depositados. Embora não haja uma regra exata de separação pelas informações obtidas, definiu-se a área 1 como contendo resíduos mais novos (até dois anos), a área 2 com resíduos de idade até 6 anos e a área 3 com resíduos depositados há mais de 6 anos. A Figura 1 apresenta o levantamento planialtimétrico simplificado do aterro e as áreas identificadas.

Com intuito de identificar o estágio de biodegradação em cada área do aterro conforme a idade dos resíduos sólidos depositados, cada área do aterro foi associada às fases de biodecomposição propostas por Tchobanoglous et al (1993): Ajuste Inicial (fase I), Transição (fase II), Ácida (fase III), Metanogênica (fase IV) e Maturação (fase V), como ilustra a Figura 2. Os períodos de tempo de cada fase são variáveis, dependendo de fatores como umidade e temperatura da região.

As três primeiras fases ocorrem comumente 


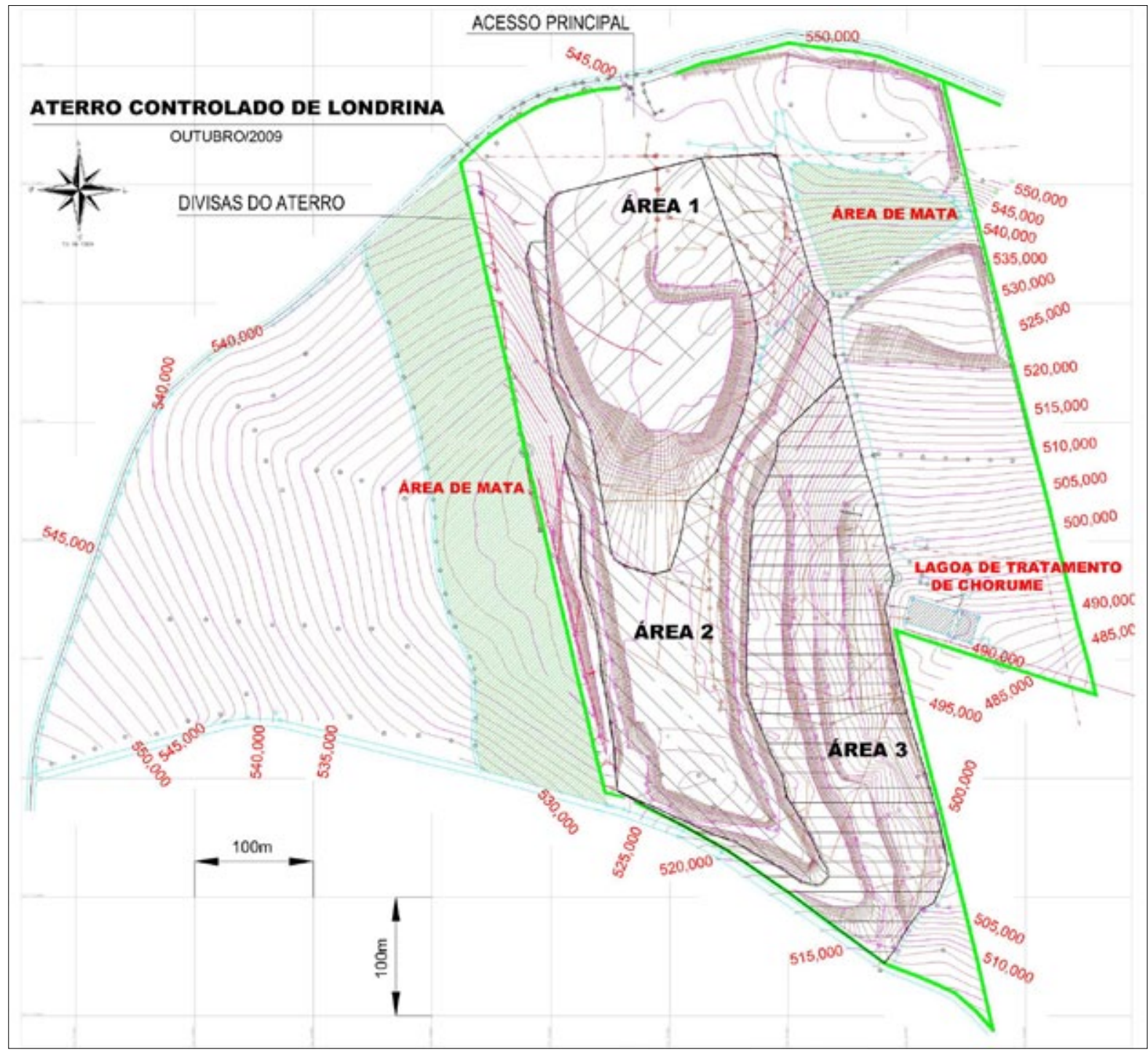

Figura 1: Levantamento planialtimétrico simplificado do aterro controlado de Londrina em 10/2009, com a identificação das áreas de operação selecionadas pela idade dos resíduos sólidos depositados.

em períodos de tempo mais curtos na biodegradação dos aterros e foram associadas à área 1 do aterro controlado de Londrina, já que os resíduos eram depositados nesta área nos últimos 2 anos até o encerramento do mesmo. A quarta fase tem por característica fundamental maior produção de metano e se prolonga por períodos de tempo mais longos, sendo associada à área 2 do aterro, que era utilizada para deposição dos resíduos antes da área 1. A quinta fase, fase de declínio na produção de biogás e de estabilização da matéria orgânica foi associada à área 3 do aterro, tratando-se da área mais antiga de todas. A Figura 2 mostra as diversas fases da biodegradação em aterros segundo Tchobanoglous et al (1993).

\section{Medições das emissões de biogás}

Os ensaios realizados na camada de superfície do aterro controlado de Londrina foram produzidos utilizando-se uma placa estática de fluxo, com dimensões de 0,40m x 0,40m x 0,05m, caracterizada por reter o biogás em seu ambiente interno enquanto o mesmo é monitorado.

Os equipamentos empregados nas campanhas de medidas foram: um medidor de gases Draeger $\mathrm{x}$-Am 7000, com possibilidade de leitura volumétrica dos gases $\mathrm{CH}_{4}, \mathrm{CO}_{2}, \mathrm{O}_{2}$ e $\mathrm{H}_{2} \mathrm{~S}$, um termômetro digital com sensor e faixa de medição de 


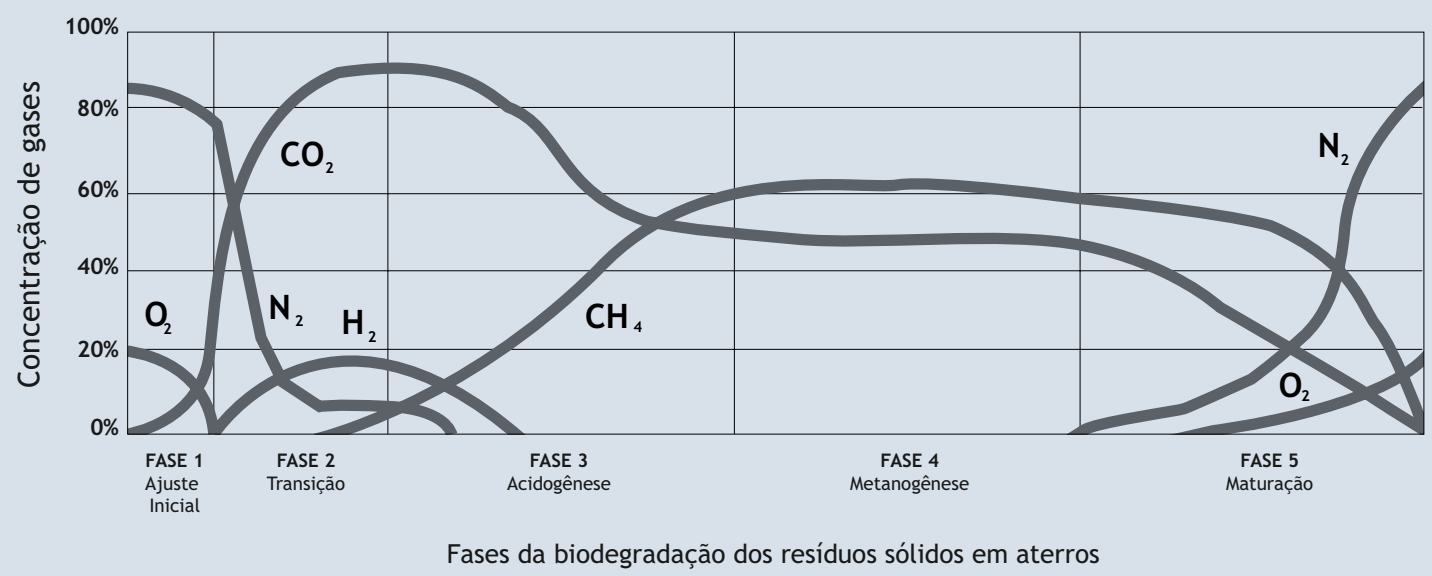

Fonte: TCHOBANOGLOUS et al (1993)

Figura 2: Dinâmica da geração dos principais gases componentes do biogás em aterros de resíduos sólidos segundo Tchobanoglous

$-50^{\circ} \mathrm{C}$ a $1200^{\circ} \mathrm{C}$ e uma placa de fluxo com dimensões de 0,40x0,40x0,05m, de acordo com a metodologia utilizada por Maciel (2003). A pressão atmosférica necessária à normalização dos gases foi fornecida pelo Instituto Agronômico do Paraná (IAPAR) - Estação Londrina, e ajustada para a altitude do aterro.

A velocidade de saída do biogás emitido pelos drenos verticais foi avaliada por meio de um termo-anemômetro digital com faixa de leitura de 0 a $20 \mathrm{~m} / \mathrm{s}$ para a velocidade (resolução de 0,01 $\mathrm{m} / \mathrm{s}$ ) e com faixa de leitura de 0 a $80^{\circ} \mathrm{C}$ para a temperatura, para conseqüente cálculo da vazão. A caracterização desses gases realizou-se por meio do medidor de gases Draeger x-Am 7000. Com intuito de obter a vazão do biogás emitido pelo dreno, media-se a velocidade do biogás em pelo menos três pontos da seção interna do tubo.

A quantificação do gás metano e do gás carbônico emitidos através da camada de cobertura foi feita a partir da média estatística dos valores obtidos nos ensaios com placa de fluxo, aplicados separadamente em cada área selecionada. A soma dos valores de emissão obtidos para cada gás $\left(\mathrm{CH}_{4}\right.$ e $\left.\mathrm{CO}_{2}\right)$ nas três áreas de origem resultou no volume total do respectivo gás para cada campanha.

Para estimar a quantidade de resíduos sólidos depositados no aterro controlado de Londrina ao longo dos anos de sua atividade, inicialmente levantou-se a população desse período. O Instituto
Brasileiro de Geografia e Estatística (IBGE, 2010) forneceu alguns dados de população para o município de Londrina no período de 1979 (início das operações do aterro), até o ano de 2010, quando o aterro encerrou suas atividades. As populações dos anos intermediários às populações dos anos fornecidos pelo IBGE foram calculadas considerando um crescimento linear entre os dados existentes e também por meio de dados de pesagens, embora estes últimos não tenham sido realizados sistematicamente.

Com relação à quantidade de resíduos sólidos produzidos pelo município de Londrina e depositados no aterro controlado, utilizou-se o valor per capita de 700 g/hab.dia. (Tabela 7), conforme média histórica informada pela Prefeitura de Londrina.

\subsection{Campanhas de medidas realizadas no aterro controlado de Londrina}

Foram realizadas três campanhas de medidas no aterro controlado de Londrina: a primeira em outubro de 2009, a segunda no mês de setembro de 2010 e a terceira campanha em novembro de 2010 .

A primeira campanha de medidas foi realizada em conjunto com os pesquisadores da Universidade Federal de Pernambuco (MACIEL et al, 2009) em outubro de 2009. O clima da região se apresentava em meio a uma primavera chuvosa.

A segunda campanha de medidas se realizou 
nos dias 4, 5, 6, 7 e 17 de setembro de 2010, por meio da equipe de pesquisa da Universidade Estadual de Londrina. $\mathrm{O}$ clima da região na ocasião da campanha se mostrava em fins de um inverno com estiagem prolongada.

A terceira campanha de medidas aconteceu nos dias 29, 30 e 31 de outubro e 01 e 02 de novembro de 2010 pela Universidade Estadual de Londrina. O clima da região na ocasião se apresentava em início da época típica de chuvas, com 298 milímetros de precipitação computados entre a segunda e a terceira campanhas.

As áreas 1, 2 e 3 do aterro, selecionadas conforme a idade dos resíduos sólidos depositados, apresentaram pequenas alterações nas dimensões devido ao período de operação no aterro

\begin{tabular}{|c|c|c|c|c|c|}
\hline Campanha & \multicolumn{2}{|r|}{ Dados dos Ensaios } & Area 1 & Área 2 & Area 3 \\
\hline \multirow{8}{*}{1} & \multicolumn{2}{|r|}{ Área superficial $\left(\mathrm{m}^{2}\right)$} & 42.809 & 55.328 & 49.852 \\
\hline & \multirow{3}{*}{$\begin{array}{l}\text { Ensaios com } \\
\text { placa de fluxo }\end{array}$} & Número dos ensaios & 3 & 2 & 0 \\
\hline & & EP-01, EP-02 e EP-05 & $x$ & - & - \\
\hline & & EP-03 e EP-04 & - & $x$ & - \\
\hline & \multirow{4}{*}{$\begin{array}{l}\text { Ensaios com } \\
\text { drenos verticais }\end{array}$} & Número dos ensaios & 5 & 2 & 5 \\
\hline & & DV-01 a DV-05 & $x$ & - & - \\
\hline & & DV-06 a DV-07 & - & $x$ & - \\
\hline & & DV-08 a DV-12 & - & - & $x$ \\
\hline \multirow{9}{*}{2} & \multicolumn{2}{|c|}{ Área superficial $\left(\mathrm{m}^{2}\right)$} & 51.535 & 50.506 & 49.852 \\
\hline & \multirow{4}{*}{$\begin{array}{l}\text { Ensaios com } \\
\text { placa de fluxo }\end{array}$} & Número dos ensaios & 19 & 3 & 6 \\
\hline & & $\mathrm{P}-01$ a P13 e P-17 a P-22 & $x$ & - & - \\
\hline & & P-23 a P-25 & - & $x$ & - \\
\hline & & P-26 a P-31 & - & - & $x$ \\
\hline & \multirow{4}{*}{$\begin{array}{l}\text { Ensaios com } \\
\text { drenos verticais }\end{array}$} & Número dos ensaios & 15 & 1 & 3 \\
\hline & & DA-01 a DA-05 e DAN-13 a DAN-22 & $x$ & - & - \\
\hline & & DA-07 & - & $x$ & - \\
\hline & & DA-08 a DA-10 & - & - & $x$ \\
\hline \multirow{9}{*}{3} & \multicolumn{2}{|r|}{ Área superficial $\left(\mathrm{m}^{2}\right)$} & 51.535 & 50.506 & 49.852 \\
\hline & \multirow{4}{*}{$\begin{array}{l}\text { Ensaios com } \\
\text { placa de fluxo }\end{array}$} & Número dos ensaios & 21 & 8 & 7 \\
\hline & & PT-01 a PT-21 & $x$ & - & - \\
\hline & & PT-22 a PT-29 & - & $x$ & - \\
\hline & & PT-30 a PT-36 & - & - & $x$ \\
\hline & \multirow{4}{*}{$\begin{array}{l}\text { Ensaios com } \\
\text { drenos verticais }\end{array}$} & Número dos ensaios & 14 & 2 & 3 \\
\hline & & DA-02 a DA-05 e DAN-13 a DAN-22 & $x$ & - & - \\
\hline & & DA-07 a DAN-23 & - & $x$ & - \\
\hline & & DA-08 a DA-10 & - & - & $x$ \\
\hline
\end{tabular}

Notas:

Os drenos foram nomeados de DV para DA a partir da campanha 2, mas a numeração foi mantida

Os drenos DAN foram implantados no aterro entre as campanhas 1 e 2

Os drenos DV-06, DV-11 e DV-12 foram extintos pelas operadoras do aterro entre as campanhas 1 e 2

$O$ dreno DA-01 foi extinto pela operadora do aterro entre as campanhas 2 e 3

Os ensaios P-14 a P-16 da campanha 2 foram realizados fora das áreas definidas e não obtiveram resultados em termos de gás metano Os ensaios P-13 e PT-09 não foram considerados na média por apresentarem vazão de metano excessiva para ensaios com placa de fluxo $O$ ensaio $P$-28 não apresentou emissão de gás metano

Tabela 1: Caracterização dos ensaios realizados durante as campanhas de medidas 1, 2 e 3 


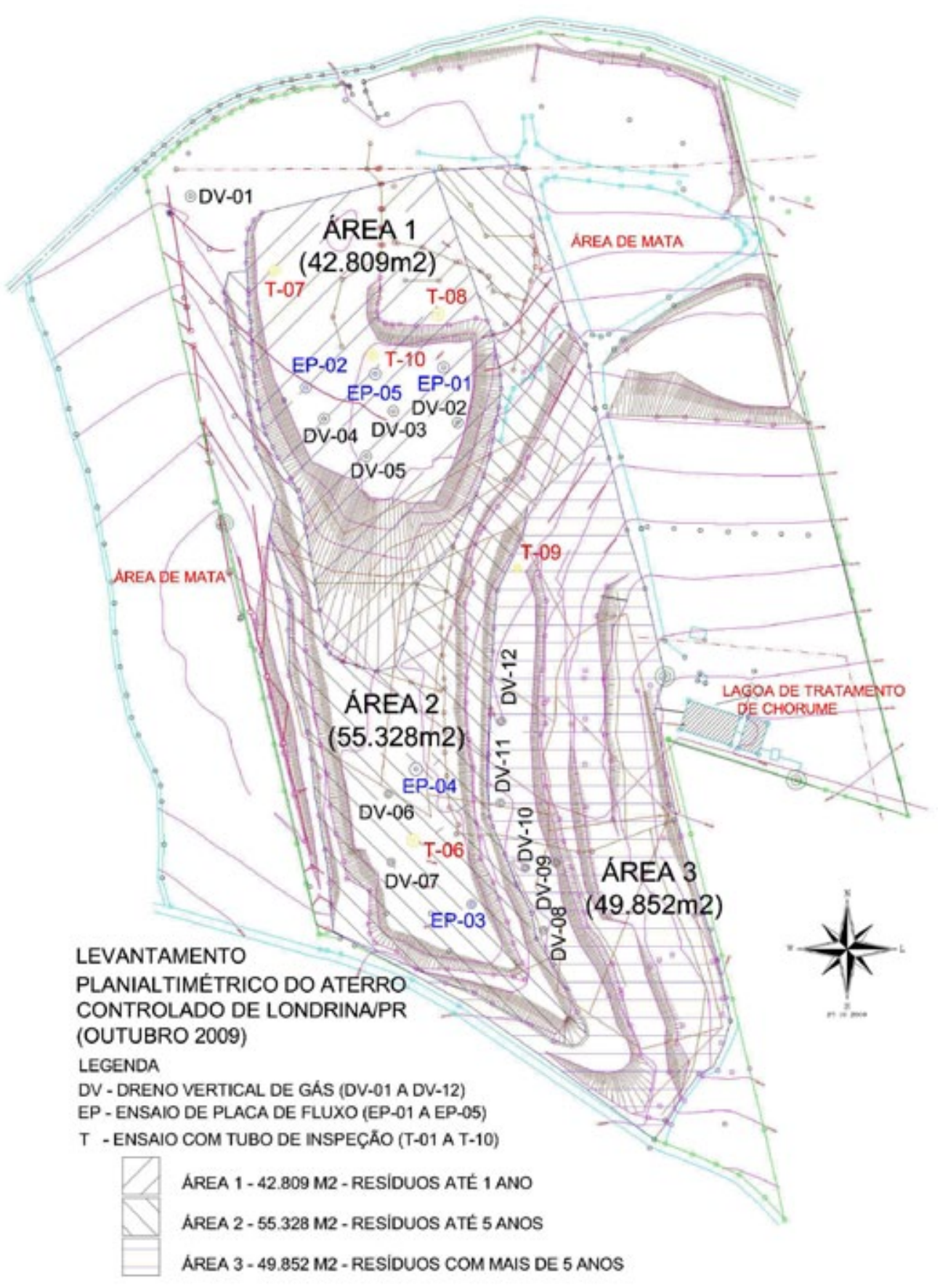

\begin{tabular}{c|c|c}
\multicolumn{3}{|c}{ Área 1} \\
\hline \multirow{2}{*}{ Ensaio } & \multicolumn{2}{|c}{ Coordenadas } \\
\cline { 2 - 3 } & $\mathrm{X}$ & $\mathrm{Y}$ \\
\hline EP-01 & 209,26 & 596,55 \\
\hline EP-02 & 112,94 & 582,67 \\
\hline & & \\
\hline & & \\
\hline EP-05 & 161,54 & 591,95
\end{tabular}

\begin{tabular}{c|c|c}
\multicolumn{3}{c}{ Área 2 } \\
\hline \multirow{2}{*}{ Ensaio } & \multicolumn{2}{|c}{ Coordenadas } \\
\cline { 2 - 3 } & $\mathrm{X}$ & $\mathrm{Y}$ \\
\hline & & \\
\hline & & \\
\hline EP-03 & 228,94 & 220,80 \\
\hline EP-04 & 189,79 & 315,29 \\
\hline & & \\
\hline
\end{tabular}

Figura 3: Localização dos pontos de ensaios realizados na campanha de medidas 1 
entre a primeira e a segunda campanha. Entre a segunda e terceira campanha de medidas não houve alterações significativas nas dimensões das áreas, motivado pelo fato das campanhas terem sido realizadas em datas relativamente próximas.

Em todas as campanhas foram utilizados formulários padronizados na coleta das leituras de campo e os dados foram transferidos para planilhas previamente montadas. A Tabela 1 esclarece a nomenclatura, os tipos e o número de ensaios realizados em cada campanha.

A locação dos pontos de ensaios com placa de fluxo e dos drenos verticais existentes na camada de superfície do aterro controlado de Londrina foi definida considerando-se as áreas 1, 2 e 3 previamente estabelecidas.

As Figuras 3, 4 e 5 apresentam as posições dos ensaios no aterro controlado de Londrina nas campanhas de medidas 1,2 e 3 , respectivamente.

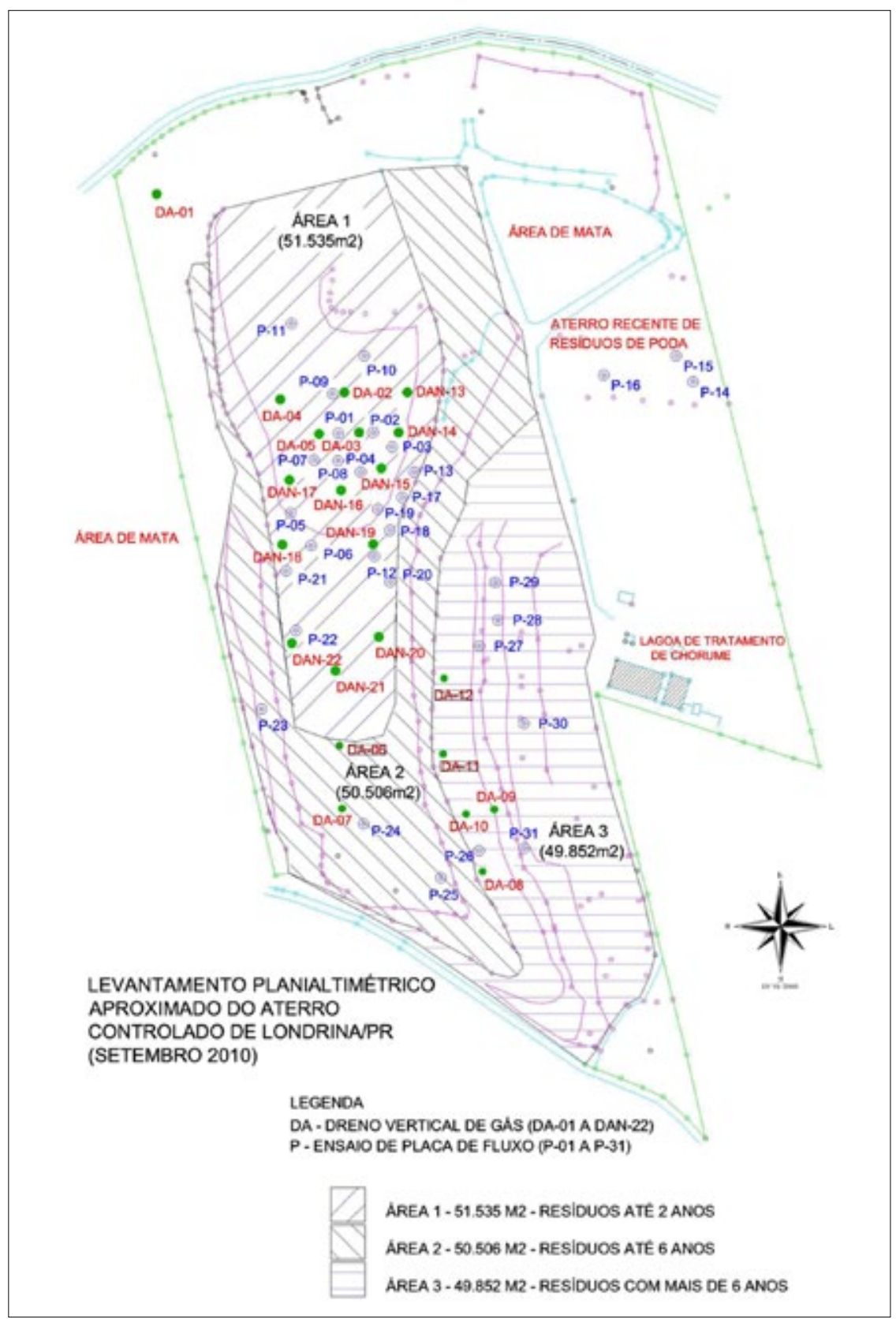

ÁREA 1

\begin{tabular}{c|c|c}
\multirow{2}{*}{ Ensaio } & \multicolumn{2}{|c}{ Coordenadas } \\
\cline { 2 - 3 } & $\mathrm{X}$ & $\mathrm{Y}$ \\
\hline $\mathrm{P}-01$ & 135,52 & 602,43 \\
\hline P-02 & 149,03 & 574,00 \\
\hline P-03 & 179,98 & 590,29 \\
\hline P-04 & 229,38 & 615,42 \\
\hline P-05 & 226,62 & 587,74 \\
\hline P-06 & 218,89 & 550,27 \\
\hline P-07 & 177,31 & 539,38 \\
\hline P-08 & 167,88 & 526,74 \\
\hline P-09 & 168,16 & 509,74 \\
\hline P-10 & 206,12 & 525,02 \\
\hline P-11 & 166,23 & 473,79 \\
\hline P-12 & 146,77 & 489,14 \\
\hline P-13 & 112,64 & 559,02 \\
\hline P-14 & 186,65 & 457,30 \\
\hline P-15 & 132,40 & 458,85 \\
\hline P-16 & 129,95 & 410,27 \\
\hline P-17 & 132,85 & 387,64 \\
\hline P-18 & 134,25 & 364,14 \\
\hline P-19 & 195,33 & 355,26 \\
\hline P-20 & 201,15 & 393,70 \\
\hline P-21 & 202,78 & 421,16
\end{tabular}

ÁREA 2

\begin{tabular}{c|c|c}
\multirow{2}{*}{ Ensaio } & \multicolumn{2}{|c}{ Coordenadas } \\
\cline { 2 - 3 } & $\mathrm{X}$ & $\mathrm{Y}$ \\
\hline P-22 & 280,71 & 544,34 \\
\hline P-23 & 255,60 & 539,87 \\
\hline P-24 & 246,97 & 510,91 \\
\hline P-25 & 224,78 & 470,01 \\
\hline P-26 & 219,84 & 419,07 \\
\hline P-27 & 223,98 & 247,93 \\
\hline P-28 & 233,99 & 222,43 \\
\hline P-29 & 192,79 & 235,11 \\
& ÁREA 3 \\
&
\end{tabular}

\begin{tabular}{c|c|c}
\multirow{2}{*}{ Ensaio } & \multicolumn{2}{|c}{ Coordenadas } \\
\cline { 2 - 3 } & $\mathrm{X}$ & $\mathrm{Y}$ \\
\hline P-30 & 276,02 & 220,93 \\
\hline P-31 & 269,11 & 235,62 \\
\hline P-32 & 296,95 & 231,73 \\
\hline P-33 & 313,98 & 308,55 \\
\hline P-34 & 275,76 & 355,52 \\
\hline P-35 & 287,23 & 393,84 \\
\hline P-36 & 276,97 & 404,49 \\
\hline
\end{tabular}

Figura 4: Localização dos pontos de ensaios realizados na campanha de medidas 2. 


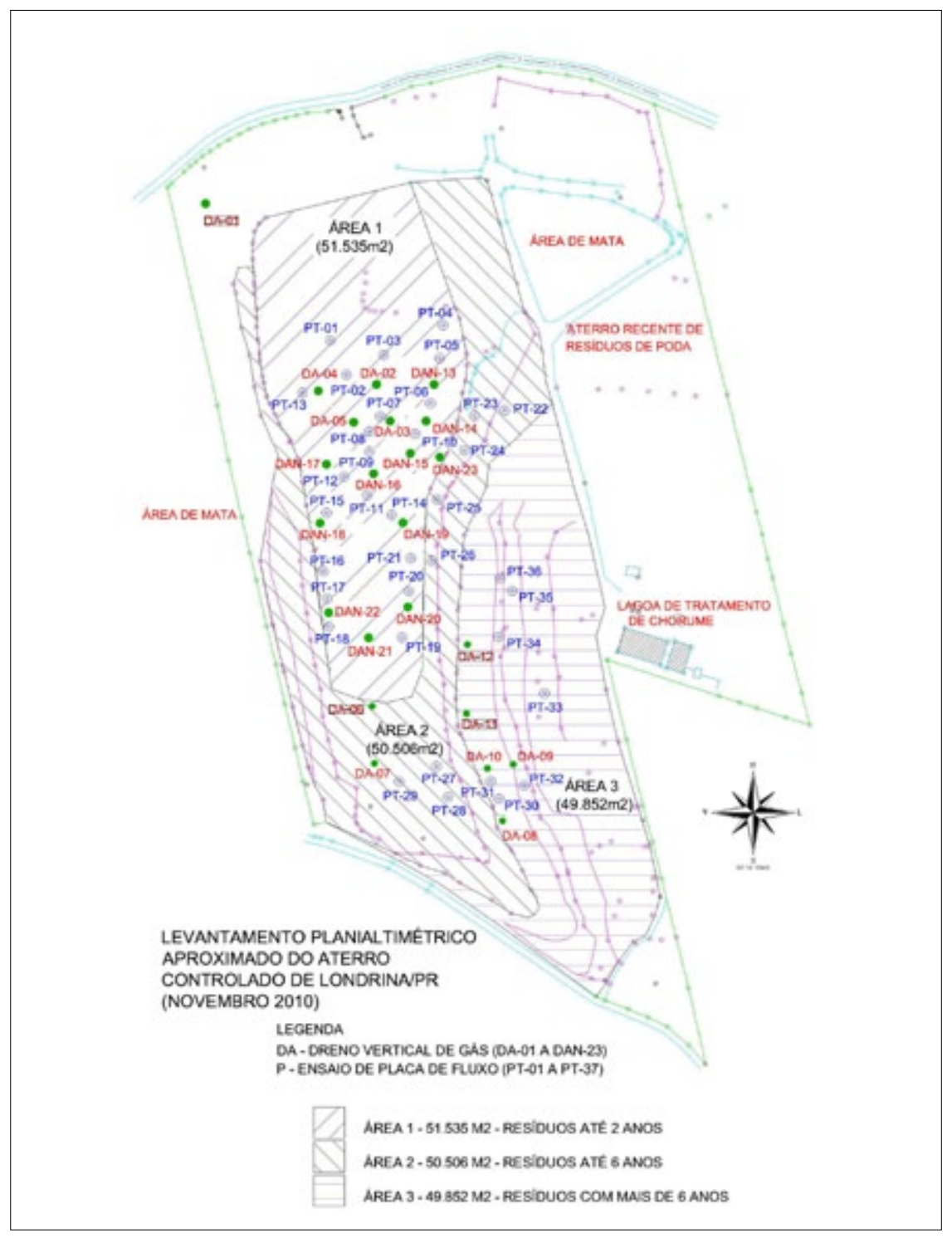

\begin{tabular}{|c|c|c|}
\hline \multicolumn{3}{|c|}{ ÁREA 1} \\
\hline \multirow{2}{*}{ Ensaio } & \multicolumn{2}{|c|}{ Coordenadas } \\
\hline & $X$ & $Y$ \\
\hline PT-01 & 169,66 & 535,04 \\
\hline PT-02 & 195,76 & 535,66 \\
\hline PT-03 & 210,35 & 524,61 \\
\hline PT-04 & 169,28 & 514,15 \\
\hline PT-05 & 133,39 & 474,55 \\
\hline PT-06 & 149,08 & 449,81 \\
\hline PT-07 & 151,07 & 514,70 \\
\hline PT-08 & 186,51 & 505,80 \\
\hline PT-09 & 165,26 & 564,85 \\
\hline PT-10 & 189,27 & 593,84 \\
\hline PT-11 & 133,90 & 618,10 \\
\hline PT-12 & 196,86 & 441,69 \\
\hline PT-13 & 227,14 & 505,50 \\
\hline PT-14 & 438,67 & 574,02 \\
\hline PT-15 & 425,87 & 593,80 \\
\hline PT-16 & 370,86 & 579,26 \\
\hline PT-17 & 217,85 & 486,39 \\
\hline PT-18 & 208,56 & 461,22 \\
\hline PT-19 & 199,71 & 477,44 \\
\hline PT-20 & 208,87 & 422,07 \\
\hline PT-21 & 129,71 & 430,55 \\
\hline PT-22 & 137,38 & 385,25 \\
\hline \multicolumn{3}{|c|}{ ÁREA 2} \\
\hline \multirow{2}{*}{ Ensaio } & \multicolumn{2}{|c|}{ Coordenadas } \\
\hline & $X$ & $Y$ \\
\hline PT-23 & 111,20 & 325,92 \\
\hline PT-24 & 188,58 & 238,69 \\
\hline PT-25 & 247,30 & 197,65 \\
\hline \multicolumn{3}{|c|}{ ÁREA 3} \\
\hline \multirow{2}{*}{ Ensaio } & \multicolumn{2}{|c|}{ Coordenadas } \\
\hline & $\mathrm{X}$ & $Y$ \\
\hline PT-26 & 276,48 & 218,49 \\
\hline PT-27 & 276,67 & 373,60 \\
\hline PT-28 & 290,63 & 393,32 \\
\hline PT-29 & 288,56 & 422,00 \\
\hline PT-30 & 310,48 & 314,83 \\
\hline PT-31 & 310,69 & 220,08 \\
\hline
\end{tabular}

Figura 5: Localização dos pontos de ensaios realizados na campanha de medidas 3.

Posteriormente à coleta dos dados de campo, as leituras obtidas foram tratadas para normalização do gás metano e do dióxido de carbono por meio da equação dos gases ideais.

\section{Tratamento dos dados obtidos no aterro}

Após coletados os dados na superfície do aterro controlado de Londrina, os valores de emissão de gases foram normalizados por meio da equação dos gases ideais, corrigindo a densidade do gás metano e do dióxido de carbono em relação à CNTP. Os valores de emissão na superfície do aterro obtidos com os ensaios de placa de fluxo foram tratados estatisticamente, por meio do método de interpolação denominado inverso ponderado da distância com expoente " 2 " (IQD), escolhido por ser propício para amostras heterogêneas.

Traçaram-se coordenadas cartesianas da posição de cada ensaio e utilizou-se o valor de emissão de biogás nos pontos com terceira coordenada. Os fluxos de gases conquistados nos ensaios com placa de fluxo foram avaliados estatisticamente considerando cada área (1, 2 e 3) separadamente, com intuito de se obter a média das emissões na área em questão. O procedimento descrito foi repetido nas três campanhas de medidas. 


\section{Modelos matemáticos de previsão de produ-} ção de biogás

Para estimar a produção de biogás foram utilizados três modelos matemáticos: o modelo sugerido pela Agencia Ambiental Americana para resíduos municipais (USEPA, 1998), o Software Landgem 3.02, também indicado pela Agência Ambiental Americana (USEPA, 2005) e o modelo de primeira ordem do Painel Intergovernamental de Mudanças Climáticas (IPCC, 1996).

\section{Modelo teórico sugerido pela Agencia Ambien- tal Americana para resíduos municipais (USEPA, 1998)}

O modelo USEPA (1998) é apresentado em um documento da entidade na seção que trata de aterros municipais de resíduos sólidos ("2.4 Municipal Solid Waste Landfills - MSW"). Adotou-se o modelo "sem controle de emissão", caso característico da maioria dos aterros de resíduos sólidos no Brasil e também do aterro controlado de Londrina. A configuração matemática para calcular a produção de gás metano é apresentada na equação 1 , bem como os parâmetros adotados para aplicação do modelo.

$$
Q_{C H 4}=L_{0} \cdot R \cdot\left(e^{-k \cdot c}-e^{-k \cdot t}\right)
$$

equação 1

Onde:

$\mathrm{QCH}_{4}=$ quantidade de metano produzida por ano ( $\left.\mathrm{m}^{3} / \mathrm{ano}\right)$

$k=$ taxa de geração de metano $\left(0,05\right.$ ano $\left.^{-1}\right)$

$L_{o}=$ potencial da geração de metano $\left(170 \mathrm{~m}^{3}\right.$ de $\mathrm{CH}_{4} /$ ton . resíduo)

$R$ = taxa média anual de resíduos sólidos recebidos durante a vida ativa do aterro (ton./ano) => tabela 7

$t$ = tempo desde o início do depósito dos RSD (32 anos)

$c=$ tempo desde $o$ fechamento do aterro (anos); $c=0$ para aterros ativos

e = base log, sem unidade.

\section{Software Landgem 3.02 sugerido pela Agencia} Ambiental Americana (USEPA, 2005)

Para quantificar as emissões de gases produzidas a partir da biodegradação dos RSD, o programa emprega uma equação de primeira ordem. O software possibilita ainda calcular as emissões de metano, dióxido de carbono, NMOCs ("nonmethane organic compounds") e outros poluentes atmosféricos. A equação matemática 2 é utilizada pelo programa para estimar a produção de gás metano em aterros. Os parâmetros utilizados para entrada no modelo foram os sugeridos pela USEPA (2005).

$$
Q_{C H 4}=\sum_{i=1}^{n} \sum_{j=0.1}^{1} k \cdot L_{o} \cdot\left[\frac{M_{i}}{10}\right] \cdot\left(e^{-k \cdot t_{i, j}}\right)
$$

equação 2

Onde:

$\mathrm{QCH}_{4}=$ quantidade de metano produzida por ano ( $\left.\mathrm{m}^{3} / \mathrm{ano}\right)$

$i=1$ - tempo em anos a ser incrementado

$n=$ ano do inventário (2010)

$j=0,1-$ tempo em anos a ser incrementado

$k=$ taxa de geração de metano $\left(0.05\right.$ ano $\left.^{-1}\right)$

$L_{o}=$ potencial da geração de metano $\left(170 \mathrm{~m}^{3}\right.$ de $\mathrm{CH}_{4} /$ ton . resíduo)

Mi = massa de resíduos sólidos recebidos no ano "i" (ton./ ano) $=>$ tabela 7

$t=$ idade da seção " $j$ " dos resíduos $M_{i}$ recebidos no ano "i"

(anos com decimal, p.e., 3.2 anos)

Modelo de primeira ordem adotado pelo Painel Intergovernamental de Mudanças Climáticas (IPCC, 1996)

O Painel Intergovernamental de Mudanças Climáticas (IPCC, 1996) apresenta algumas metodologias para estimar as emissões de gás metano para a atmosfera. A metodologia de primeira ordem proposta está expressa na configuração matemática exibida na equação 3. Os parâmetros adotados são sugeridos pela referida entidade.

$C H_{4 \text { gerado }}=\sum_{i=1}^{t}\left(A \cdot k \cdot \operatorname{RSD}_{T}(x) \cdot \operatorname{RSD} f(x) \cdot L_{O} \cdot e^{(-k \cdot(t-x))}\right)$

equação 3

Onde:

$\mathrm{CH}_{4}$ gerado = geração de gás metano no ano (ton. de $\mathrm{CH}_{4}$ ) ano)

$R S D_{T}=$ total de resíduos gerados pela população no ano " $x$ " (ton. de resíduo/ano) => Tabela 7

$R S D_{f}=$ fração de resíduos sólidos efetivamente depositada no aterro no ano " $x$ " (100\%)

$L_{o}=$ potencial de geração de metano médio calculado $(85,91$

$\mathrm{m}^{3} \mathrm{CH}_{4}$ /ton. resíduo)

$A=(1-e-k) / k$; fator de normalização para corrigir a soma

$k=$ taxa de geração de metano $\left(0,05\right.$ ano $\left.^{-1}\right)$

$e=$ base logarítmica (sem unidade)

$t=$ ano de realização do inventário (2010)

$x=$ ano de contribuição desde $o$ início das atividades do aterro até $o$ ano " $t$ " (32 anos). 


\section{Resultados e discussões}

\section{Resultados das medições de emissões de bio- gás}

\subsection{Resultados da primeira campanha de me- dida}

A primeira campanha de ensaios foi considerada preliminar devido ao limite amostral de ensaios com placa estática de fluxo. Com relação aos ensaios realizados nos drenos verticais, somente um dreno existente no aterro não pode ser avaliado na ocasião.

A Tabela 2 mostra os resultados de quantificação de gás metano na primeira campanha de medidas, considerando os valores obtidos para as emissões na camada de superfície e somando com os valores de vazão de gás metano obtidos nos drenos verticais.

Os resultados de emissão superficial de gás metano variaram entre 1,3 a 30,6 NL/h.m². Em média, os valores registrados em toda a superfície do aterro marcaram 13,9 NL/h.m², ou 238,3 $\mathrm{g} /$ dia. $\mathrm{m}^{2}$ em termos de vazão mássica. A camada de cobertura se apresentava bastante úmida devido a fortes chuvas que ocorriam na ocasião da campanha.

Com relação aos drenos verticais, os resultados da emissão de gás metano variaram de 0 a 190,2 $\mathrm{Nm}^{3} / \mathrm{h}$. O dreno de maior vazão se localizava na área 2, apresentado RSD em fase de biodegradação tipicamente metanogênica, conforme a idade dos resíduos da área em questão (até 6 anos) e confirmado pelas características dos gases emitidos.

\begin{tabular}{|c|c|c|c|c|c|c|}
\hline $\begin{array}{l}\text { Tipo de } \\
\text { ensaio }\end{array}$ & \multicolumn{2}{|c|}{ Dados dos ensaios } & Área1 & Área 2 & Área 3 & Total \\
\hline \multirow{8}{*}{ 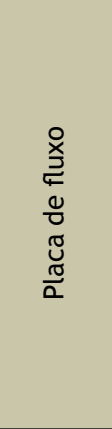 } & \multicolumn{2}{|c|}{ Número de ensaios } & 3 & 2 & 0 & - \\
\hline & \multirow{6}{*}{$\begin{array}{c}\text { Fluxo de } \\
\text { metano } \\
\left(\mathrm{Nm}^{3} / \mathrm{m}^{2} / \mathrm{ano}\right)\end{array}$} & EP-01 & 50,81 & - & - & - \\
\hline & & EP-02 & 11,39 & - & - & - \\
\hline & & EP-03 & - & 45,18 & - & - \\
\hline & & EP-04 & - & 268,05 & - & - \\
\hline & & EP-05 & 231,36 & - & - & - \\
\hline & & Média & 129,18 & 158,12 & - & - \\
\hline & $\begin{array}{l}\text { Emissão na } \\
\text { área }\end{array}$ & $\mathrm{Nm}^{3} / \mathrm{ano}$ & 5.530 .067 & 8.748 .463 & - & 14.278 .530 \\
\hline \multirow{14}{*}{ 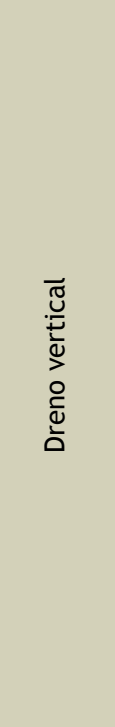 } & \multirow{13}{*}{$\begin{array}{c}\text { Emissão } \\
\text { de metano } \\
\left(\mathrm{Nm}^{3} / \mathrm{h}\right)\end{array}$} & DV-01 & 0,00 & - & - & - \\
\hline & & DV-02 & 3,80 & - & - & - \\
\hline & & DV-03 & * & - & - & - \\
\hline & & DV-04 & 13,10 & - & - & - \\
\hline & & DV-05 & 10,70 & - & - & - \\
\hline & & DV-06 & - & 0,00 & & \\
\hline & & DV-07 & - & 190,20 & & \\
\hline & & DV-08 & - & - & 36,90 & \\
\hline & & DV-09 & - & - & 0,00 & \\
\hline & & DV-10 & - & - & 10,50 & \\
\hline & & DV-11 & - & - & 7,00 & \\
\hline & & DV-12 & - & - & 20,30 & \\
\hline & & Total & 27,60 & 190,20 & 74,70 & - \\
\hline & $\begin{array}{c}\text { Emissão na } \\
\text { área }\end{array}$ & $\mathrm{Nm}^{3} / \mathrm{ano}$ & 241.776 & 1.666 .152 & 654.372 & 2.562 .300 \\
\hline \multicolumn{2}{|c|}{ Total geral } & $\mathrm{Nm}^{3} /$ ano & - & - & - & 16.840 .830 \\
\hline
\end{tabular}

Tabela 2: Resultados dos ensaios de medição de emissões de metano na primeira campanha de medidas 
Os resultados finais da primeira campanha mostraram que $14.278 .530 \mathrm{Nm}^{3}$ /ano de gás metano vazavam pela camada de cobertura do aterro, enquanto que $2.562 .300 \mathrm{Nm}^{3} /$ ano foram emitidos pelos drenos na ocasião dessa campanha. $\mathrm{O}$ valor total de emissões de gás metano, considerando as emissões pela superfície e pelos drenos verticais registraram $16.840 .830 \mathrm{Nm}^{3} / \mathrm{ano}$.

Na primeira campanha os resultados referentes às emissões de dióxido de carbono foram considerados iguais aos de gás metano para composição do biogás emitido no aterro. Desta forma, o volume total de biogás considerado na primeira campanha de medidas foi de 33.681 .660 Nm³/ano de biogás.

\subsection{Resultados da segunda campanha de medidas}

A composição dos dados existentes na tabela 3 segue os mesmos procedimentos utilizados na Tabela 2 da primeira campanha de medidas.

Relacionaram-se os ensaios com placa de fluxo conforme a área em que estavam inseridos e foram obtidas as médias pelo método estatístico IQD. As médias foram aplicadas conforme as dimensões de cada área para obtenção da emissão superficial parcial. A somatória das emissões nas áreas resultou a emissão superficial total do aterro.

Os resultados obtidos nos ensaios com placa de fluxo variaram de 0,88 NL/h.m² a 48,24 NL/h. $\mathrm{m}^{2}$, com média de $10,24 \mathrm{NL} / \mathrm{h} \cdot \mathrm{m}^{2}$, valor equivalente a $175,5 \mathrm{~g} /$ dia.m ${ }^{2}$ em termos de vazão mássica. A média obtida para toda a superfície foi menor que a alcançada na primeira campanha de medidas. Os ensaios P-14, P-15 e P-16 foram utilizados para monitoramento de gases em áreas externas à área do aterro, mas não apresentaram leitura de gás metano.

Os drenos verticais exibiram valores de emissão variando de $0,07 \mathrm{Nm}^{3} / \mathrm{h}$ (DA-01) a 42,28 $\mathrm{Nm}^{3} / \mathrm{h}$ (DA-07). 0 dreno 07 novamente apresentou maior vazão de gases do que os outros drenos, conforme observado na primeira campanha de medidas. Entretanto, o valor obtido foi cerca de quatro vezes menor do que o valor conquistado na primeira campanha. $\mathrm{O}$ motivo deste fato pode se relacionar ao estrangulamento do dreno para instalação de um queimador em sua extremidade, que poderia propiciar grande perda de carga e consequente fuga de gases.

A segunda campanha registrou emissão total de gás metano de $16.247 .368 \mathrm{Nm}^{3} /$ ano. A emissão pela camada de cobertura do aterro contro- lado de Londrina registrou $89,2 \%$ do total de emissões de gás metano. As emissões por drenos diminuíram em relação à primeira campanha, ficando com a parcela restante.

Repetindo os cálculos e os procedimentos para o dióxido de carbono, o valor da emissão total na superfície para este gás foi de 15.252 .520 $\mathrm{Nm}^{3} /$ ano e o valor da emissão por drenos foi de $1.477 .900 \mathrm{Nm}^{3} /$ ano de dióxido de carbono, totalizando $16.730 .419 \mathrm{Nm}^{3}$ /ano.

O valor total das emissões de biogás na segunda campanha, considerando a soma do gás metano e do dióxido de carbono, anotou o valor de $32.977 .786 \mathrm{Nm}^{3}$ /ano. O volume registrado foi pouco inferior ao da primeira campanha de medidas.

\subsection{Resultados da terceira campanha de medidas}

A terceira campanha de medidas seguiu os métodos e procedimentos das campanhas anteriores. Na Tabela 4 são apresentados os resultados obtidos nos ensaios com placa estática de fluxo.

Os ensaios com placa de fluxo apresentaram variabilidade de resultados entre $0,05 \mathrm{NL} / \mathrm{h} \cdot \mathrm{m}^{2}$ (PT-01) e 92,99 NL/h.m² (PT-12). A média geral de todos os resultados foi de $12,72 \mathrm{NL} / \mathrm{h} . \mathrm{m}^{2}$ (equivalente a 218,1 g/dia.m²), valor inferior a média da primeira campanha e superior à média da segunda campanha de medidas.

Os drenos verticais mostraram valores variando entre $0 \mathrm{Nm}^{3} / \mathrm{h}$ (DA-09) e $37,59 \mathrm{Nm}^{3} / \mathrm{h}$ no dreno DAN-18. O dreno DA-07 apresentou vazão elevada $\left(28,29 \mathrm{Nm}^{3} / \mathrm{h}\right)$, mas inferior ao dreno DAN18. De forma geral, a vazão por drenos diminuiu sucessivamente nas três campanhas, apesar do incremento do número de drenos pela operadora do aterro, demonstrando a ineficácia do sistema aplicado no aterro controlado de Londrina. A vazão de gás metano por drenos na terceira campanha representou 7,9\% do total da emissão do gás obtido na campanha.

O volume total de gás metano medido na terceira campanha foi de 19.090.103 Nm³/ano. Repetindo os procedimentos de cálculo para o dióxido de carbono, obtiveram-se os volumes de $1.405 .630 \mathrm{Nm}^{3} /$ ano para os drenos e 16.041 .015 $\mathrm{Nm}^{3}$ /ano para a camada de superfície do aterro, perfazendo 17.446.644 Nm³/ano de dióxido de carbono na terceira campanha.

Considerando o volume total de biogás estimado na terceira campanha como a soma dos volumes de gás metano e de dióxido de carbono, 


\begin{tabular}{|c|c|c|c|c|c|c|}
\hline Tipo de ensaio & \multirow{2}{*}{\multicolumn{2}{|c|}{$\begin{array}{l}\text { Dados dos ensaios } \\
\text { Número de ensaios }\end{array}$}} & Área 1 & Área 2 & Área 3 & Total \\
\hline \multirow{30}{*}{ 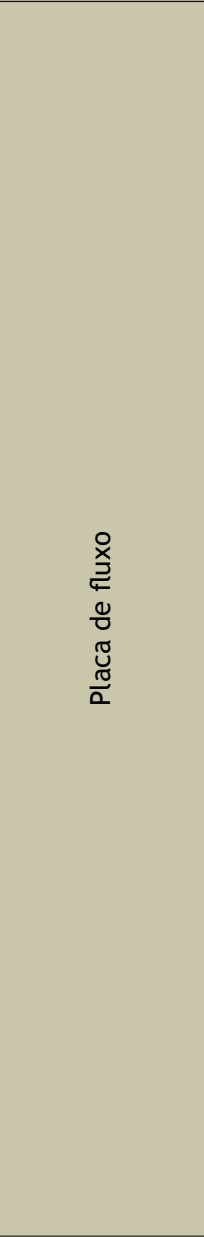 } & & & 3 & 2 & 0 & - \\
\hline & \multirow{28}{*}{$\begin{array}{l}\text { Fluxo de metano } \\
\left(\mathrm{Nm}^{3} / \mathrm{m}^{2} / \mathrm{ano}\right)\end{array}$} & $\mathrm{P}-01$ & 7,74 & - & - & - \\
\hline & & $\mathrm{P}-02$ & 43,97 & - & - & - \\
\hline & & P-03 & 57,22 & - & - & - \\
\hline & & P-04 & 16,40 & - & - & - \\
\hline & & $\mathrm{P}-05$ & 66,79 & - & - & - \\
\hline & & P-06 & 11,20 & - & - & - \\
\hline & & P-07 & 133,50 & - & - & - \\
\hline & & P-08 & 285,63 & - & - & - \\
\hline & & P-09 & 16,87 & - & - & - \\
\hline & & $\mathrm{P}-10$ & 61,54 & - & - & - \\
\hline & & $\mathrm{P}-11$ & 28,54 & - & - & - \\
\hline & & $\mathrm{P}-12$ & 12,89 & - & - & - \\
\hline & & $\mathrm{P}-17$ & 38,78 & - & - & - \\
\hline & & $\mathrm{P}-18$ & 422,57 & - & - & - \\
\hline & & P-19 & 104,00 & - & - & - \\
\hline & & P-20 & 67,18 & - & - & - \\
\hline & & $P-21$ & 193,73 & - & - & - \\
\hline & & $\mathrm{P}-22$ & 28,15 & - & - & - \\
\hline & & $\mathrm{P}-23$ & - & 329,83 & - & - \\
\hline & & $\mathrm{P}-24$ & - & 93,21 & - & - \\
\hline & & $\mathrm{P}-25$ & - & 149,13 & - & - \\
\hline & & $\mathrm{P}-26$ & - & - & 109,42 & - \\
\hline & & $\mathrm{P}-27$ & - & - & 43,39 & - \\
\hline & & P-28 & - & - & - & - \\
\hline & & P-29 & - & - & 21,49 & - \\
\hline & & $\mathrm{P}-30$ & - & - & 18,01 & - \\
\hline & & $\mathrm{P}-31$ & - & - & 26,43 & - \\
\hline & & Média IQD & 82,67 & 164,19 & 38,91 & - \\
\hline & Emissão na área & $\mathrm{Nm}^{3} /$ ano & 4.260 .398 & 8.292 .580 & 1.939 .741 & 14.492 .720 \\
\hline \multirow{21}{*}{ 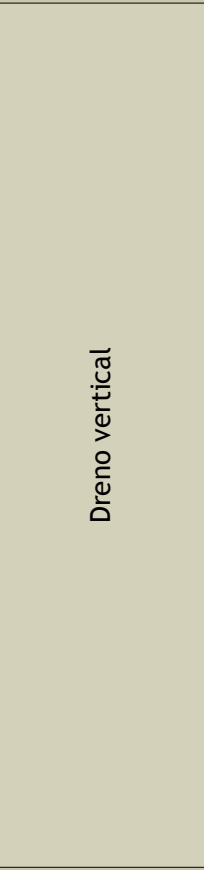 } & \multirow{20}{*}{$\begin{array}{c}\text { Emissão de } \\
\text { metano }\left(\mathrm{Nm}^{3} / \mathrm{h}\right)\end{array}$} & DA-01 & 0,12 & - & - & - \\
\hline & & DA-02 & 2,66 & - & - & - \\
\hline & & DA-03 & 3,14 & - & - & - \\
\hline & & DA-04 & 2,75 & - & - & - \\
\hline & & DA-05 & 4,88 & - & - & - \\
\hline & & DA-07 & - & 42,28 & - & - \\
\hline & & DA-08 & - & - & 11,84 & - \\
\hline & & DA-09 & - & - & 0,07 & - \\
\hline & & DA-10 & - & - & 11,77 & - \\
\hline & & DAN-13 & 8,49 & - & - & - \\
\hline & & DAN-14 & 1,98 & - & - & - \\
\hline & & DAN-15 & 3,00 & - & - & - \\
\hline & & DAN-16 & 20,85 & - & - & - \\
\hline & & DAN-17 & 2,33 & - & - & - \\
\hline & & DAN-18 & 35,85 & - & - & - \\
\hline & & DAN-19 & 17,32 & - & - & - \\
\hline & & DAN-20 & 16,35 & - & - & - \\
\hline & & DAN-21 & 5,04 & - & - & - \\
\hline & & DAN-22 & 9,60 & - & - & - \\
\hline & & Total & 134,34 & 42,28 & 23,69 & - \\
\hline & Ensaio na área & $\mathrm{Nm}^{3} / \mathrm{ano}$ & 1.176 .817 & 370.335 & 207.496 & 1.754 .648 \\
\hline \multicolumn{2}{|c|}{ Total geral } & $\mathrm{Nm}^{3} / \mathrm{ano}$ & - & - & - & 16.247 .368 \\
\hline
\end{tabular}

Tabela 3: Resultados dos ensaios de medição de emissões de metano na segunda campanha de medidas 


\section{Artigo Técnico}

\begin{tabular}{|c|c|c|c|c|c|c|}
\hline Tipo de ensaio & \multicolumn{2}{|c|}{ Dados dos ensaios } & Área 1 & Área 2 & Área 3 & Total \\
\hline \multirow{38}{*}{ 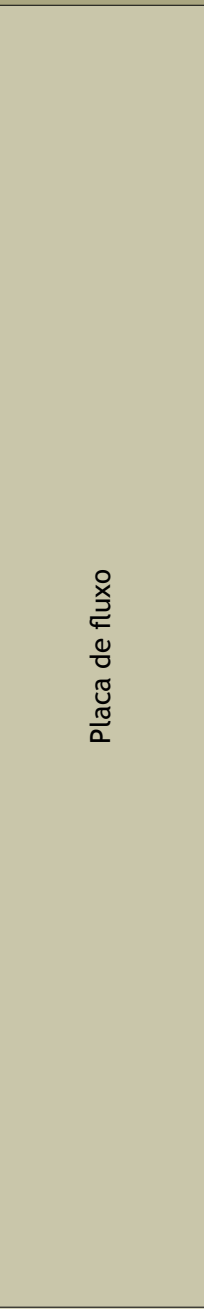 } & \multicolumn{2}{|c|}{ Número de ensaios } & 3 & 2 & 0 & - \\
\hline & \multirow{36}{*}{$\begin{array}{c}\text { Fluxo de metano } \\
\left(\mathrm{Nm}^{3} / \mathrm{m}^{2} / \mathrm{ano}\right)\end{array}$} & PT-01 & 4,37 & - & - & - \\
\hline & & PT-02 & 30,49 & - & - & - \\
\hline & & PT-03 & 87,11 & - & - & - \\
\hline & & PT-04 & 23,38 & - & - & - \\
\hline & & PT-05 & 13,64 & - & - & - \\
\hline & & PT-06 & 47,74 & - & - & - \\
\hline & & PT-07 & 20,39 & - & - & - \\
\hline & & PT-08 & 18,00 & - & - & - \\
\hline & & PT-10 & 69,80 & - & - & - \\
\hline & & PT-11 & 654,25 & - & - & - \\
\hline & & PT-12 & 816,52 & - & - & - \\
\hline & & PT-13 & 73,69 & - & - & - \\
\hline & & PT-14 & 23,18 & - & - & - \\
\hline & & PT-15 & 138,12 & - & - & - \\
\hline & & PT-16 & 53,71 & - & - & - \\
\hline & & PT-17 & 18,93 & - & - & - \\
\hline & & PT-18 & 54,16 & - & - & - \\
\hline & & PT-19 & 23,71 & - & - & - \\
\hline & & PT-20 & 13,32 & - & - & - \\
\hline & & PT-21 & 17,10 & - & - & - \\
\hline & & PT-22 & - & 18,15 & - & - \\
\hline & & PT-23 & - & 25,66 & - & - \\
\hline & & PT-24 & - & 310,42 & - & - \\
\hline & & PT-25 & - & 466,40 & - & - \\
\hline & & PT-26 & - & 7,38 & - & - \\
\hline & & PT-27 & - & 11,00 & - & - \\
\hline & & PT-28 & - & 31,90 & - & - \\
\hline & & PT-29 & - & 517,52 & - & - \\
\hline & & PT-30 & - & - & 13,30 & - \\
\hline & & PT-31 & - & - & 8,69 & - \\
\hline & & PT-32 & - & - & 170,44 & - \\
\hline & & PT-33 & - & - & 55,44 & - \\
\hline & & PT-34 & - & - & 44,60 & - \\
\hline & & PT-35 & - & - & 10,22 & - \\
\hline & & PT-36 & - & - & 17,00 & - \\
\hline & & Média IQD & 122,10 & 171,15 & 52,96 & - \\
\hline & Emissão na área & $\mathrm{Nm}^{3} / \mathrm{ano}$ & 6.292 .424 & 8.644 .102 & 2.640 .162 & 17.576 .687 \\
\hline \multirow{22}{*}{ 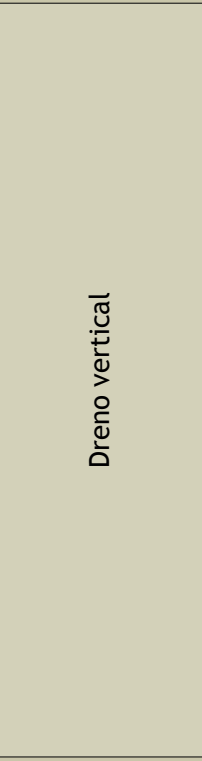 } & \multirow{21}{*}{$\begin{array}{c}\text { Emissão de } \\
\text { metano }\left(\mathrm{Nm}^{3} / \mathrm{h}\right)\end{array}$} & DA-02 & 1,14 & - & - & - \\
\hline & & DA-03 & 2,64 & - & - & - \\
\hline & & DA-04 & 2.14 & - & - & - \\
\hline & & DA-05 & 4,57 & - & - & - \\
\hline & & DA-07 & - & 28,79 & - & - \\
\hline & & DA-08 & - & - & 5,21 & - \\
\hline & & DA-09 & - & - & 0,00 & - \\
\hline & & DA-10 & - & - & 1,62 & - \\
\hline & & DAN-13 & 3,18 & - & - & - \\
\hline & & DAN-14 & 1,62 & - & - & - \\
\hline & & DAN-15 & 0,85 & - & - & - \\
\hline & & DAN-16 & 13,76 & - & - & - \\
\hline & & DAN-17 & 3,28 & - & - & - \\
\hline & & DAN-18 & 37,59 & - & - & - \\
\hline & & DAN-19 & 4,46 & - & - & - \\
\hline & & DAN-20 & 10,56 & - & - & - \\
\hline & & DAN-21 & 1,23 & - & - & - \\
\hline & & DAN-22 & 14,62 & - & - & - \\
\hline & & DAN-23 & 35,50 & - & - & - \\
\hline & & DAN-24 & - & - & - & - \\
\hline & & Total & 137,14 & 28,79 & 6,84 & - \\
\hline & Emissão na área & $\mathrm{Nm}^{3} / \mathrm{ano}$ & 1.201 .337 & 252.171 & 59.907 & 1.513 .415 \\
\hline \multicolumn{2}{|c|}{ Total geral } & $\mathrm{Nm}^{3} / \mathrm{ano}$ & - & - & - & 19.090 .103 \\
\hline
\end{tabular}

Tabela 4: Resultados dos ensaios de medição de emissões de metano na terceira campanha de medidas 
totalizou-se $36.536 .747 \mathrm{Nm}^{3} /$ ano de biogás. O volume registrado foi superior ao das duas campanhas anteriores, mas relativamente próximo aos outros volumes de biogás.

\section{Resultados obtidos com a utilização dos mode-} los matemáticos

Os modelos matemáticos quantificaram o bio- gás produzido no aterro desde o início das operações até o ano de encerramento das atividades em 2010, perfazendo 32 anos de operação do aterro controlado de Londrina. Para tal foram necessárias estimativas populacionais do município com objetivo de quantificar os RSD produzidos durante os anos de operação. A Tabela 5 exprime esses resultados.

\begin{tabular}{|c|c|c|c|c|c|}
\hline Ano & População & $\begin{array}{c}\text { RSD } \\
\text { produzidos }\end{array}$ & $\Delta \mathrm{n}$ & População & $\begin{array}{c}\text { RSD } \\
\text { produzidos }\end{array}$ \\
\hline & $\mathrm{N}^{\circ}$ habitantes & Ton.RSD/ano & & $\mathrm{N}^{\circ}$ habitantes & Ton.RSD/ano \\
\hline 1979 & 321.536 & 82.152 & 1995 & 456.284 & 116.581 \\
\hline $1980^{*}$ & 331.510 & 84.701 & 1996 & 461.291 & 117.860 \\
\hline 1981 & 341.484 & 87.249 & $1997^{*}$ & 466.300 & 119.140 \\
\hline 1982 & 351.458 & 89.798 & 1998 & 468.374 & 119.670 \\
\hline 1983 & 361.432 & 92.346 & 1999 & 470.448 & 120.199 \\
\hline 1984 & 371.406 & 94.894 & 2000 & 472.522 & 120.729 \\
\hline 1985 & 381.380 & 97.443 & 2001 & 474.596 & 121.259 \\
\hline 1986 & 391.354 & 99.991 & 2002 & 476.670 & 121.789 \\
\hline 1987 & 401.328 & 102.539 & 2003 & 478.744 & 122.319 \\
\hline 1988 & 411.302 & 105.088 & $2004^{*}$ & 480.822 & 122.850 \\
\hline 1989 & 421.276 & 107.636 & 2005 & 484.018 & 123.667 \\
\hline $1990^{*}$ & 431.249 & 110.184 & 2006 & 487.214 & 124.483 \\
\hline 1991 & 436.256 & 111.463 & 2007 & 490.410 & 125.300 \\
\hline 1992 & 441.263 & 112.743 & 2008 & 493.606 & 126.116 \\
\hline 1993 & 446.270 & 114.022 & 2009 & 496.802 & 126.933 \\
\hline 1994 & 451.277 & 115.301 & 2010 & 500.000 & 127.750 \\
\hline
\end{tabular}

* Número de habitantes fornecido pelo IBGE (2010) 


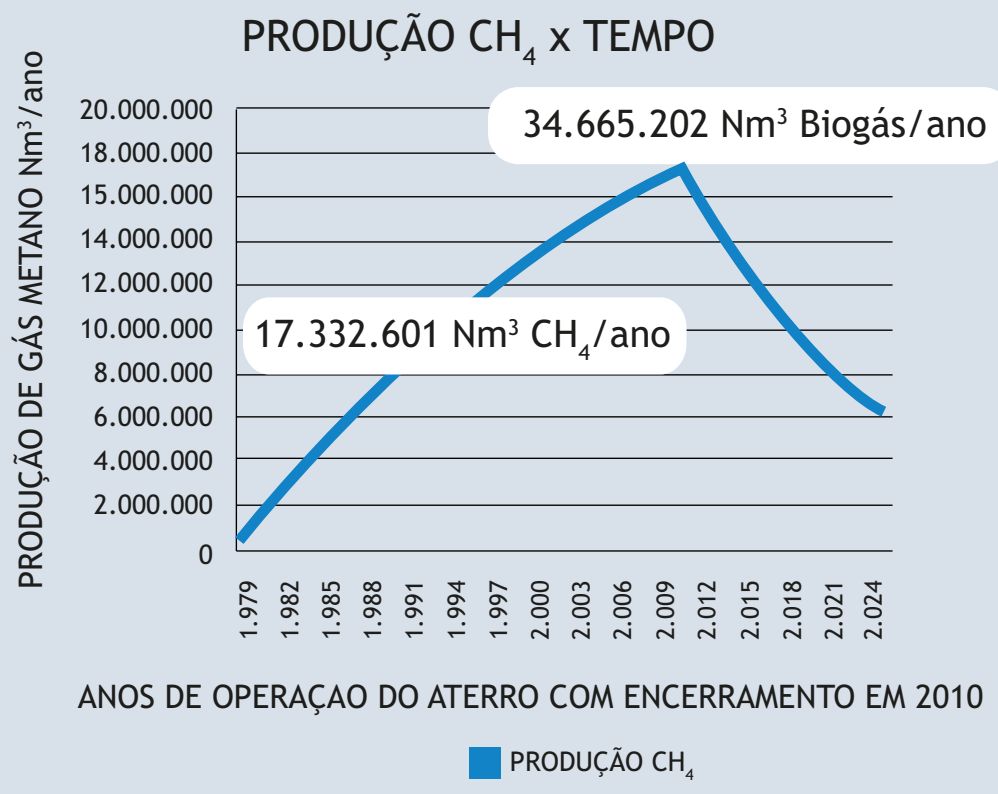

Figura 6: Comportamento gráfico obtido a partir da aplicação do modelo USEPA (1998) desde o início das atividades do aterro controlado de Londrina

\section{Modelo USEPA (1998)}

Aplicando os parâmetros admitidos para o aterro controlado de Londrina na equação apresentada, ao longo dos 32 anos, obtiveram-se os resultados apresentados na configuração gráfica da Figura 6 .

$\mathrm{O}$ volume do biogás gerado no aterro controlado de Londrina foi obtido considerando que o volume de gás carbônico se equipara ao volume de gás metano produzido. Desta forma, o volume total do biogás estimado para o aterro no ano de 2010 seria de 34.665.202 $\mathrm{Nm}^{3} /$ ano, valor obtido por meio da utilização do modelo USEPA (1998).

\section{Software Landgem 3.02}

A utilização do programa Landgem 3.02 (USEPA, 2005) para avaliar a produção de biogás no aterro controlado de Londrina possibilitou estimar o volume de gás metano, de gás carbônico e de outros gases presentes na composição final das emissões. Os resultados são exibidos na Figura 7.

O volume de gás metano produzido no ano de encerramento das atividades do aterro controlado de Londrina (2010) foi de 15.882.146 Nm³/ano. O volume de gás carbônico se igualou ao de gás metano, como admite o programa, perfazendo 31.764.293 $\mathrm{Nm}^{3} /$ ano de biogás gerado no ano de encerramento do aterro. Outros gases existentes na composição do biogás (NMOCs) quantificaram $127.057 \mathrm{Nm}^{3}$ /ano.

\section{Modelo de primeira ordem IPCC (1996)}

O modelo matemático sugerido pelo IPCC (1996) apresenta uma formulação específica para calcular o gás metano emitido pelo aterro. Considera que possa haver recuperação do gás metano emitido e avalia, inclusive, que existe um fator de oxidação do gás metano quando atravessa a camada superficial do aterro. No caso do aterro controlado de Londrina, considerou-se que não existe recuperação de gás metano e que, na ausência de dados de campo, o fator de oxidação pode ser considerado nulo. Os resultados são apresentados na Figura 8.

A estimação do volume de gás carbônico foi considerada utilizando novamente o critério de igualdade entre os dois principais gases da composição do biogás, avaliando assim 18.723.441 $\mathrm{Nm}^{3} /$ ano de gás carbônico. Assim, o volume de biogás produzido no ano de 2010 pelo modelo matemático de primeira ordem do IPCC (1996) foi de 37.446 .882 $\mathrm{Nm}^{3} /$ ano para o aterro controlado de Londrina.

\section{Resumo comparativo de resultados}

A análise comparativa tornou-se importante para avaliação da produção e das emissões de gases em cada área selecionada na respectiva campanha. Dessa forma foi possível observar a eficiência metodológica de seleção de áreas utilizadas no aterro controlado de Londrina.

Para tal, a tabela 6 apresenta os resultados com- 


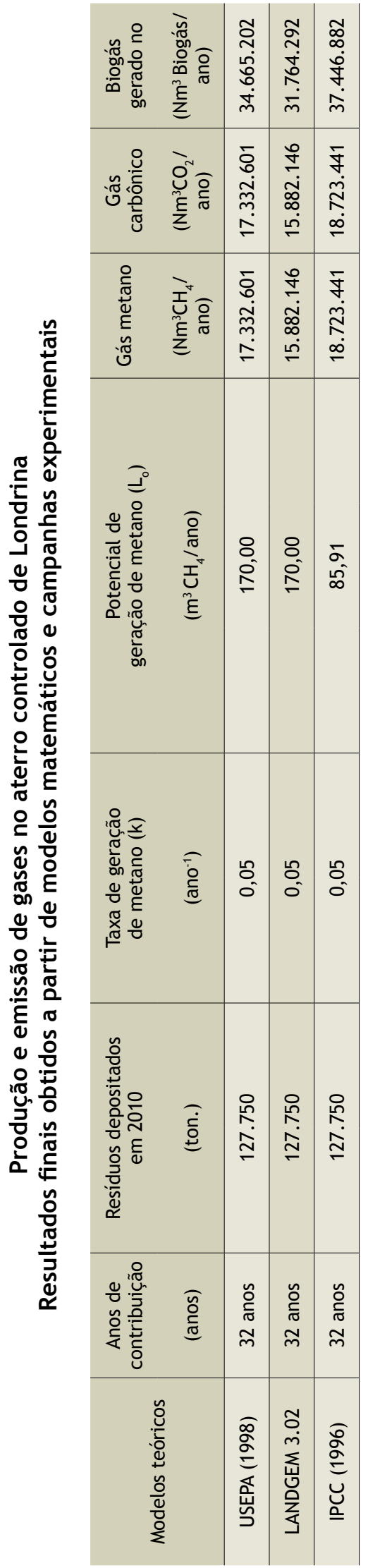

\begin{tabular}{|c|c|c|c|c|c|c|c|}
\hline 誉 & & 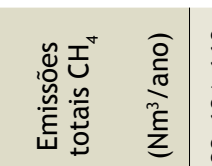 & : & 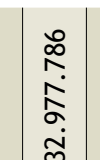 & 产 & $\mid$ & 粍 \\
\hline 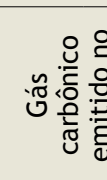 & & 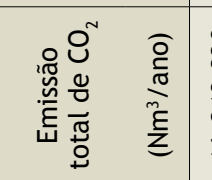 & 离 & 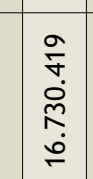 & $\stackrel{n}{\stackrel{n}{:}}$ & 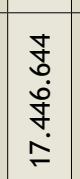 & $\stackrel{8}{\stackrel{8}{ \pm}}$ \\
\hline 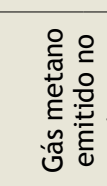 & & 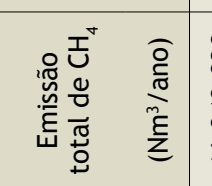 & 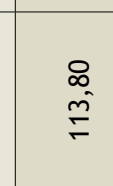 & 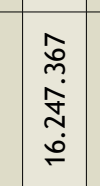 & $\begin{array}{l}\widehat{\widehat{o}} \\
\stackrel{0}{\circ}\end{array}$ & $\mid$ & 离 \\
\hline 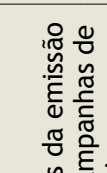 & & 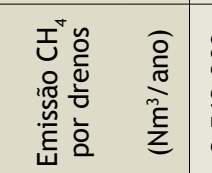 & & 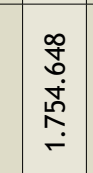 & & 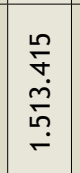 & \\
\hline 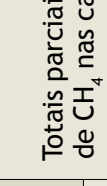 & & 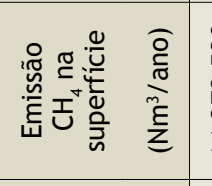 & $\stackrel{m}{=}$ & 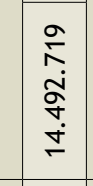 & $\stackrel{\circ}{\varrho}$ & 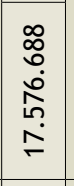 & ฐ \\
\hline 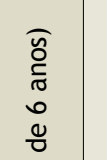 & 惫 & 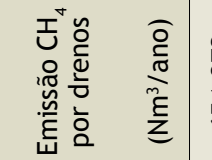 & & 总 & & $\begin{array}{l}5 \\
0 \\
0 \\
0\end{array}$ & \\
\hline$\frac{9}{4}$ & 㡲 & 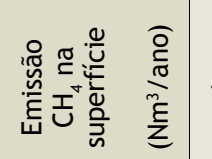 & $\stackrel{m}{m}$ & 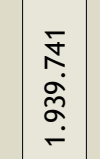 & $F$ & 总 & 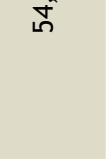 \\
\hline 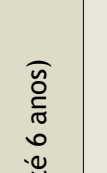 & 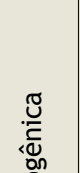 & 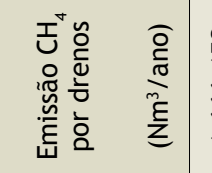 & \pm & 商 & in & 胥 & \\
\hline 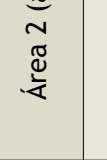 & 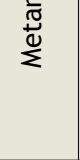 & 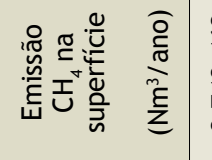 & & 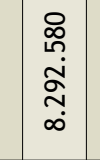 & $F$ & $\mid$ & $=$ \\
\hline 或 & 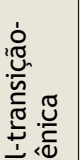 & 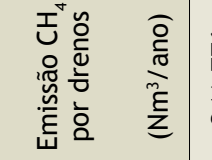 & & 竞 & & 誉 & \\
\hline 孚 & 童 & 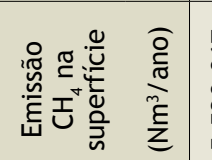 & for & 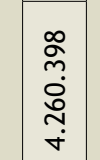 & 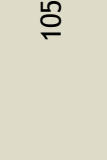 & q & 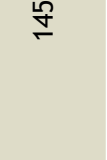 \\
\hline 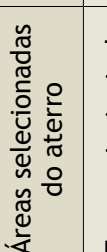 & & & 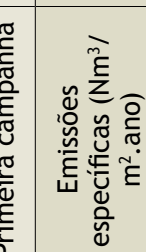 & & 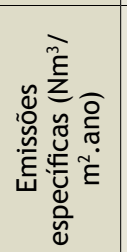 & & 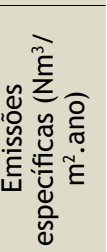 \\
\hline
\end{tabular}




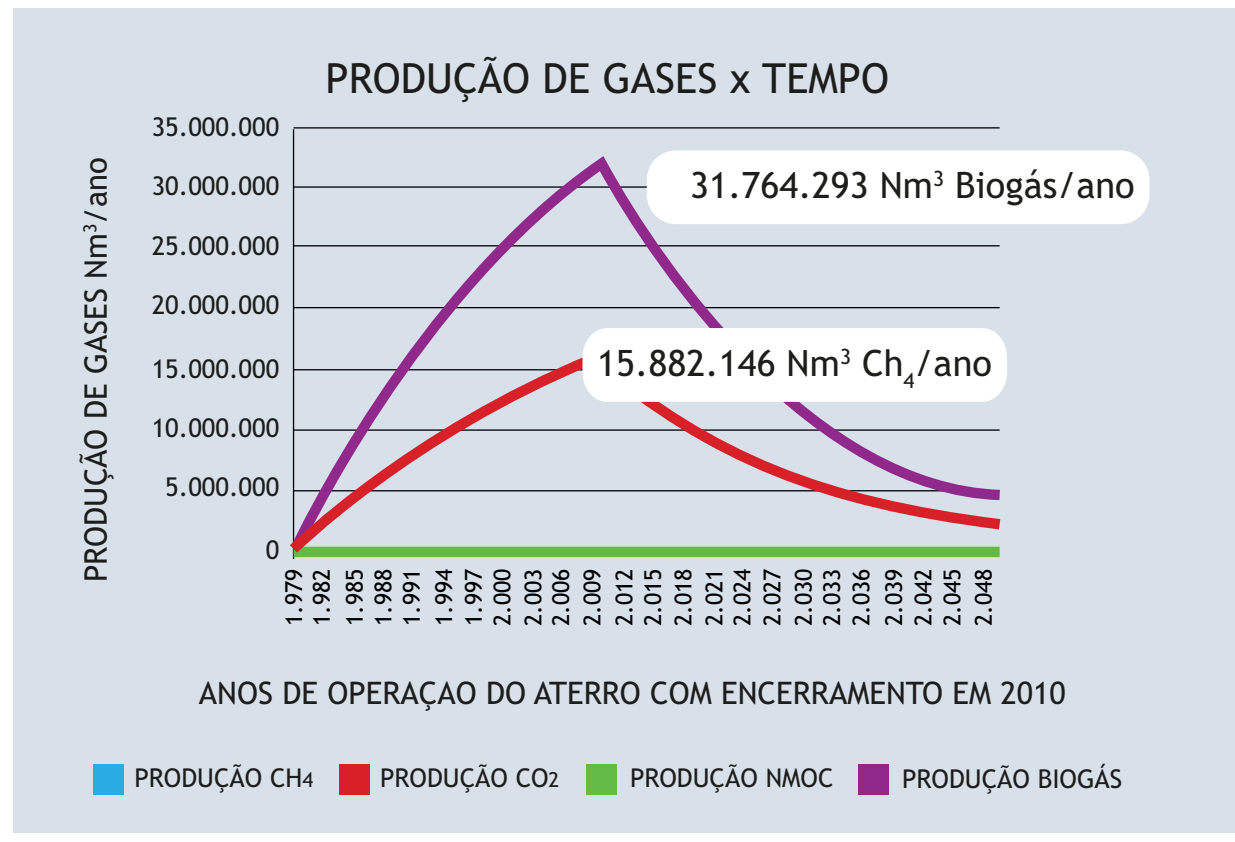

Figura 7: Comportamento gráfico obtido a partir da aplicação do software

Landgem 3.02 desde o início das atividades do aterro de Londrina

parativos das campanhas de medidas e as fases de biodegradação previamente escolhidas pela escolha do método de seleção de área por idade dos resíduos depositados

Observou-se que os valores de emissão de gás metano obtidos na camada de superfície de cada área selecionada foram consentâneos com a fase de biodegradação previamente escolhida na metodologia, seguindo a mesma ordem de grandeza. Os RSD depositados na área 2 e que deveriam ter comportamento de fase metanogênica mostraram os maiores valores de emissão, confirmado nas três campanhas. Os resíduos sólidos em fases iniciais de biodegradação (área 1) apresentaram valores intermediários de emissão nas três campanhas de medidas. Os RSD mais antigos (área 3), tipicamente em fase de maturação, também apresentaram valores de emissão concernentes a esta fase de biodegradação.

Os drenos verticais apresentaram pouca variação relativa nas campanhas, alcançando no máximo 15,2\% de participação nas emissões totais de gás metano.

Os valores de emissão total de dióxido de carbono ficaram próximos aos valores de gás metano, mostrando resultados típicos para a participação desse gás na composição do biogás de aterros.

\section{Conclusões}

1. O aterro controlado de Londrina apresentou emissão média de biogás nas três campanhas de medidas de $34.398 .731 \mathrm{Nm}^{3} / \mathrm{ano}$. As campanhas registraram diferença de $9 \%$ entre o maior e o menor volume de biogás registrado nas campanhas.

2. As campanhas de medidas mostraram que, em média, 15.449.312 $\mathrm{Nm}^{3} /$ ano de gás metano é perdida pela camada de cobertura existente na superfície do aterro, representando 88,8\% da emissão média total desse gás. $\mathrm{O}$ valor das emissões de metano nos drenos verticais representou 11,2\% (1.943.454 $\left.\mathrm{Nm}^{3} / \mathrm{ano}\right)$, demonstrando a ineficácia do sistema de drenagem.

3. Os valores médios das emissões superficiais de gás metano em suas respectivas áreas nas três campanhas mostraram coerência com as estimativas de gases produzidos nas fases de biodegradação proposta por Tchobanoglous et al (1993) para RSD. A área 2 apresentou maior valor médio de produção de metano $(178,63 \mathrm{Nm} 3 / \mathrm{m} 2$.ano), indicando fase preponderantemente metanogênica. A área 1 exibiu a segunda melhor média de emissão de gás metano (128,58 Nm3/m2.ano), denotando fases iniciais de biodegradação de RSD. A área 3 apresentou o menor valor médio de emissão de gás metano (36,79 Nm3/m2.ano), exibindo valores típicos da fase de maturação. 


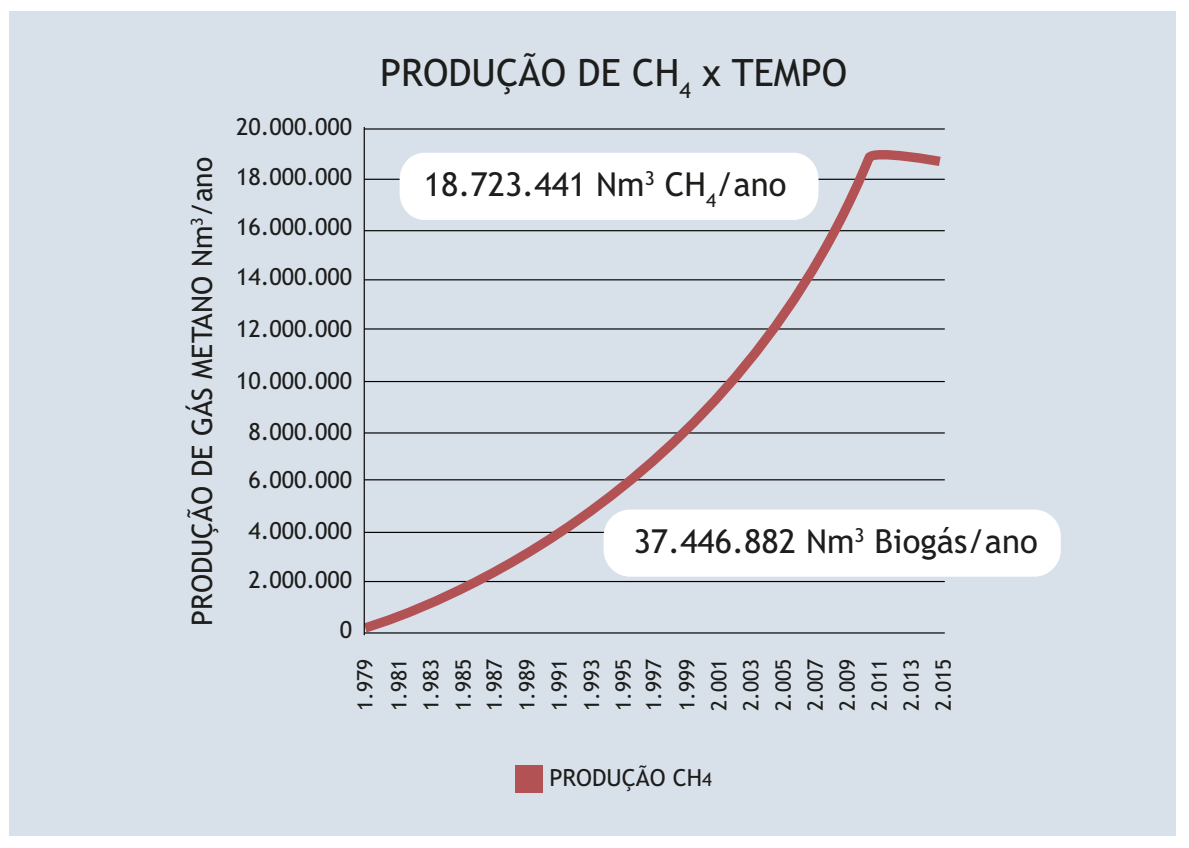

Figura 8: Comportamento gráfico obtido a partir da aplicação do modelo IPCC

(1996) desde o início das atividades do aterro de Londrina

4. Os resultados obtidos com a aplicação de modelos matemáticos mostraram os seguintes valores para o biogás produzido no aterro controlado de Londrina ao longo dos anos de operação: IPCC $(1996)=37.446 .882 \mathrm{Nm}^{3} /$ ano, USEPA $(1998)=34.665 .202 \mathrm{Nm}^{3}$ /ano e LandGEM (2005) $=31.764 .292 \mathrm{Nm}^{3} /$ ano. Estes valores divergiram pouco da média das emissões obtidas nas três campanhas de medidas (34.398.731 Nm³/ano).

\section{Referências}

1. AUDIBERT, J. L. Avaliação Qualitativa e Quantitativa do Biogás do Aterro Controlado de Londrina. Londrina. 2011. Dissertação de Mestrado. Mestrado em Engenharia de Edificações e Saneamento - Universidade Estadual de Londrina, 2011.

2. TCHOBANOGLOUS, G.; THEISEN, H.; VIGIL, S. Integrated Solid Waste Management. Engeneering Principles and Management Issues. Irwin MacGraw-Hill, 1993.

3. MACIEL, F.J.; JUCA, J.F.T. Avaliação Simplificada do Biogás do Aterro de Londrina/Pr. Relatório de Resultados. Grupo de Resíduos Sólidos. Universidade Federal de Pernambuco. Recife. Brasil. 2009.

4. MACIEL, F.J. Estudo da Geração, Percolação e Emissão de Gases no Aterro de Resíduos Sólidos da
Muribeca/Pe. Dissertação de Mestrado. Universidade Federal de Pernambuco. Recife. Brasil. 2003.

5. INSTITUTO BRASILEIRO DE GEOGRAFIA E ESTATÍSTICA (IBGE, 2010). Disponível em www.ibge. gov.br. Acesso em novembro/2010.

6. INTERNATIONAL PANEL ON CLIMATE CHANGE (IPCC, 1996). Diretrices del IPCC para los inventarios de gases de efecto invernadero, version revisada 1996. Libro de Trabajo. Modulo 6 - Desperdicios. Disponível em: www.ipcc-nggip.iges. or.jp/public/gl/spanish.htm. Acesso: julho/2010.

7. UNITED STATES ENVIRONMENTAL PROTECTION AGENCY (USEPA, 1998). Ap 42 Section 2.4 - Municipal Solid Waste Landfills, Related Information. Disponível em www.epa.gov/ttnchie1/ ap42/ch02/related/c02s04.html. Acesso em fevereiro/2010.

8. UNITED STATES ENVIRONMENTAL PROTECTION AGENCY (USEPA, 2005). Landfill Gas Emissions Model (LandGEM) Version 3.02 User's Guide. May 2005. Disponível em www.epa.gov/ttantw01/ landfill/landflpg.html. Acesso em dezembro/2010.

9. INSTITUTO BRASILEIRO DE GEOGRAFIA E ESTATÍSTICA (IBGE, 2010). Disponível em www.ibge. gov.br. Acesso em novembro 2010. 